\title{
PENYEDIAAN DATA SPASIAL BANGUNAN DI SEKOLAH VOKASI UGM DALAM SEBUAH BASISDATA 3D
}

\author{
Rochmad Muryamto ${ }^{1}$, Wahyu Marta Mutiarasari ${ }^{2}$ \\ 1,2Teknik Geomatika, Departemen Teknologi Kebumian, Sekolah Vokasi, Universitas Gadjah Mada, Indonesia \\ e-mail: ${ }^{1}$ rochmad_mury@ugm.ac.id
}

\begin{abstract}
Abstrak
Kegiatan penyediaan data spasial dapat dilakukan dengan berbagai masukan data dan menghasilkan berbagai produk. Salah satu produk yang menyimpan data spasial secara terstruktur adalah dengan basisdata spasial. Basisdata spasial bisa mendukung penyimpanan komponen ketinggian (3D) dari suatu objek, misal adalah bangunan. Penggunaan basisdata spasial 3D bisa sangat luas dan untuk berbagai bidang aplikasi, salah satunya adalah pelestarian warisan budaya. Penelitian ini bertujuan menyediakan data spasial dalam bentuk sebuah basisdata 3D untuk bangunan, terutama yang manjadi warisan budaya, di lingkungan Sekolah Vokasi (SV) UGM.

Kegiatan ini menggunakan data model 3D dari salah satu gedung di SV UGM, yaitu gedung Perpustakaan UGM. Model 3D bangunan digunakan sebagai masukan untuk merancang pemodelan basisdata. Pemodelan dalam tipe LOD 3 kemudian diterapkan dengan menggunakan CityGML, termasuk semantiknya. Hasil perancangan tersebut pada tahap selanjutnya dimasukkan ke perangkat lunak untuk membuat basisdata 3D. Tahapan analisis basisdata dilakukan dengan beberapa queri SQL untuk menguji produk penelitian berupa basisdata 3D tersebut. Hasil analisis menunjukkan data spasial 3D dapat tersimpan dengan baik. Di samping itu, beberapa semantik belum dapat diakomodasi dengan baik.
\end{abstract}

Kata kunci: data spasial, basisdata 3D, basisdata bangunan

\begin{abstract}
Spatial data supply activities can be carried out with various data inputs and produce various products. One product that stores spatially structured data is spatial database. Spatial database can support storage of height components (3D) of an object, for example a building. The use of 3D spatial database can be very broad and for various fields of application, one of which is the preservation of cultural heritage. This study aims to provide spatial data in the form of a 3D database for building, especially those that have become cultural heritage, within the UGM Vocational School (SV) environment.

This activity uses 3D model data from one of the buildings at UGM, the Vocational School library building. Building 3D model is used as input for designing database modeling. The modeling in LOD 3 is then applied using CityGML, including its semantics. The result of the design is then entered into the software to create $3 D$ database. The database analysis stage is performed with several SQL queries to test the research product in the form of the 3D database. Based on the result, 3D spatial data is stored properly using CityGML schema whereas some semantics cannot be accommodated.
\end{abstract}

Keywords: spatial data, 3D database, building database 


\section{PENDAHULUAN}

Data spasial atau data keruangan adalah data yang berkaitan dengan lokasi atau atribut suatu objek atau fenomena yang ada di permukaan bumi (Kraak dan Ormeling, 2002). Dalam rangka penyediaan data spasial, penyimpanan data yang terstruktur dalam sebuah sistem basisdata telah banyak digunakan dan dikenal masyarakat. Baik data spasial maupun data non-spasial (data atribut) dapat dikelola dalam satu lingkungan sistem manajemen basisdata yang disebut GeoDBMS (Stoter dan Oosterom, 2006).

Basisdata 3D menjadi pilihan penyimpanan data spasial pada objek yang memiliki komponen tinggi ( $z$ ), misalnya pada objek bangunan. Dalam penyimpanan data spasial bangunan yang kompleks, seperti melibatkan tematiknya, dikenal penyimpanan dengan format CityGML.

Kolbe (2009) melakukan penyajian dan pertukaran model kota 3D dengan CityGML. CityGML tidak hanya mewakili grafis saja tetapi juga meliputi semantik objek dan representasi properti tematik, taksonomi dan agregasi. Hasil penelitian menyebutkan bahwa CityGML menyeimbangkan antara kekakuan dan kelonggaran. Selain itu, menyeimbangkan antara objek sederhana dan objek dengan tematik dan struktur spasial yang kompleks serta melengkapi standar visualisasi seperti X3D atau KML.

Stadler et al (2009) menyajikan basisdata geospasial 3D yang disimpan dalam CityGML. Dalam penelitian tersebut mendiskusikan tentang optimalisasi pada model objek dan penerapannya ke dalam skema relasional. Hasil evaluasi penelitian menyebutkan penggunaan berkas yang bersamaan oleh para pengguna menunjukkan adanya peningkatan.

Subakti (2015) mengolah data lidar untuk dijadikan model kota 3D dengan format CityGML. Dalam penelitian ini, data lidar digunakan untuk membangun DTM dan pemodelan bangunan 3D. Selanjutnya, DTM dan pemodelan bangunan 3D digabung dan didefinisikan sebagai LOD 2 dengan format CityGML menggunakan perangkat lunak FME. Pemodelan tersebut digunakan untuk evaluasi koefisien dasar bangunan (KDB) dan koefisien daerah hijau (KDH) pada RTBL. Hasil menunjukkan nilai KDB minimal 25.152\%, maksimal $38.493 \%$ dan nilai $\mathrm{KDH}$ minimum $56.51 \%$, maksimal 74.40\%.

Aditya dan Laksono (2017) melakukan penelitian terhadap perangkat lunak 3DCityDB dalam menyimpan data. Data spasial diambil dari OSM kemudian dilakukan pemodelan 3D LoD1 dan disimpan dalam format CityGML. Hasilnya disampaikan melalui eksekusi queri spasial terhadap 3DCityDB.

Yang menjadi fokus CityGML adalah aspek semantik dari model kota 3D. Hal ini memungkinkan pengguna untuk melakukan analisis mendalam dan visualisasi dalam berbagai bidang aplikasi, salah satunya adalah dalam melestarikan warisan budaya (Groger dan Plumer, 2012).

Bangunan bersejarah merupakan salah satu warisan budaya yang dapat dilestarikan dengan melakukan dokumentasi untuk mempertahankan bukti fisik sejarah. Di lingkungan Sekolah Vokasi (SV) UGM yang berada di Yogyakarta, terdapat bangunan yang merupakan warisan budaya dan memiliki nilai sejarah. Kondisi bangunan yang tidak baru lagi akan rentan terhadap kerusakan, Berkaitan dengan hal tersebut, kegiatan dokumentasi bangunan bersejarah ini bertujuan untuk menyimpan data koordinat bangunan yang berguna untuk rekonstruksi.

Dilatarbelakangi hal tersebut di atas, penelitian ini bermaksud menyediakan sebuah basisdata 3D dengan format CityGML. Basisdata spasial 3D dibuat untuk menyimpan data spasial yang merepresentasikan gedung atau bangunan bersejarah. Cakupan penelitian dipersempit pada salah satu bangunan di Sekolah Vokasi UGM, yaitu gedung perpustakaan SV UGM.

Data spasial yang disimpan dalam sebuah basisdata 3D hasil penelitian ini diharapkan dapat bermanfaat dalam banyak hal, terutama untuk mendukung pelestarian bangunan bersejarah yang ada di lingkungan Sekolah Vokasi. Penyimpanan data spasial ini dapat dimanfaatkan untuk restorasi misalnya, yaitu pemulihan dalam keadaan semula gedung bersejarah jika terjadi kerusakan. Selain itu dengan penyimpanan data spasial yang terstruktur, 
dapat membantu dalam melakukan analisis SIG yang lebih kompleks.

\section{METODE}

Penelitian ini menggunakan model 3D gedung perpustakaan yang berada di lingkungan SV UGM. Model 3D tersebut digunakan sebagai data spasial masukan basisdata. Tipe pemodelan 3D ini adalah rangkaian surface yang melibatkan koordinat $x, y$ dan $z$. Karena berupa rangkaian surface, model tidak memiliki isi (volume) seperti model 3D solid.

$$
\text { Model 3D bangunan ini berupa }
$$
pemodelan LOD 3 yang disimpan dalam format DXF. Pemodelan LOD 3 merupakan pemodelan yang mencakup pendefinisan objek bangunan dengan detil. LOD3 menunjukkan model arsitektur dengan dinding rinci dan struktur atap yang berpotensi termasuk pintu dan jendela.

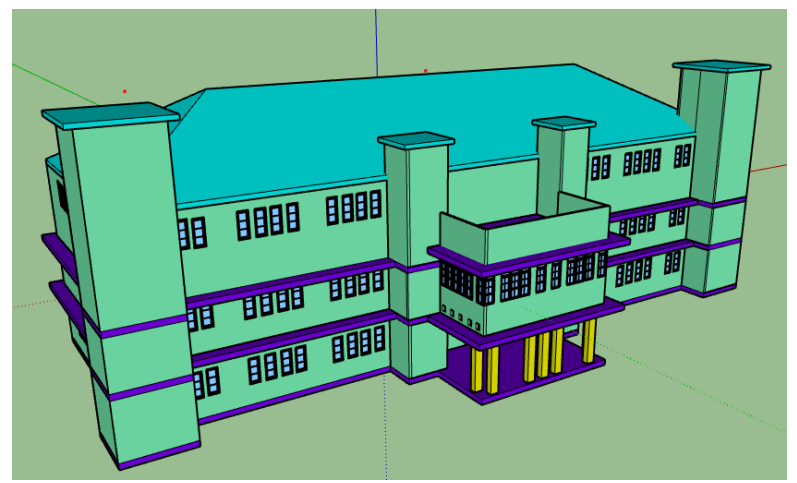

Gambar 1. Model 3D LOD 3 Gedung Perpustakaan SV

Penelitian secara umum dilakukan dalam empat tahapan setelah pengumpulan data. Tahap awal penelitian adalah melakukan konversi model 3D LOD 3 tersebut di atas, dari format DXF menjadi format CityGML. Selanjutnya dilakukan pembuatan basisdata dan memasukkan data spasial format CityGML tersebut sebagai data masukan basisdata. Beberapa queri kemudian dibuat dan dieksekusi terhadap basisdata tersebut.

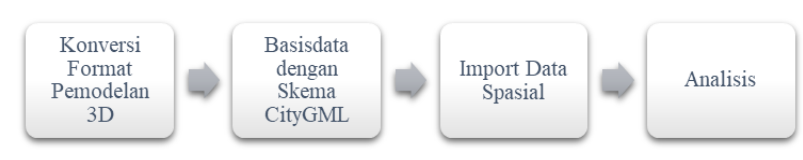

Gambar 2. Tahapan Penelitian

\section{CityGML}

CityGML adalah format data model dan merupakan $\mathrm{XML}$ berbasis terbuka untuk penyimpanan dan pertukaran model kota 3D virtual. Skema CityGML bertujuan untuk mencapai definisi umum dari entitas dasar, atribut, dan hubungan dari model kota 3D. Hal ini pada akhirnya berkaitan dengan pemeliharaan yang hemat biaya, terutama model kota 3D, dan untuk penggunaan data yang mudah dengan aplikasi yang berbeda-beda. CityGML mendefinisikan kelas dan hubungan untuk objek topografi sehubungan dengan geometri, topologi, semantik dan sifatnya.

\section{Konversi Format Data}

Tahapan konversi dilakukan untuk mendapatkan data masukan yang diinginkan dalam penelitan, yaitu format CityGML. Perangkat lunak yang digunakan dalam tahapan ini adalah Sketchup 2019 dan plugin CityEditor.

Model 3D yang berformat DXF dan diimpor ke dalam perangkat lunak memiliki sistem koordinat lokal. Sistem koordinat lokal ini adalah sistem koordinat yang digunakan dalam perangkat lunak Sketchup. Oleh karenanya, dilakukan georeferencing untuk mendapatkan model 3D dengan koordinat yang sebenarnya. Proses georeferencing dilakukan dengan menggunakan acuan koordinat hasil pengukuran di lapangan. Setelah model 3D tergeoreferensi, konversi dapat dilakukan.

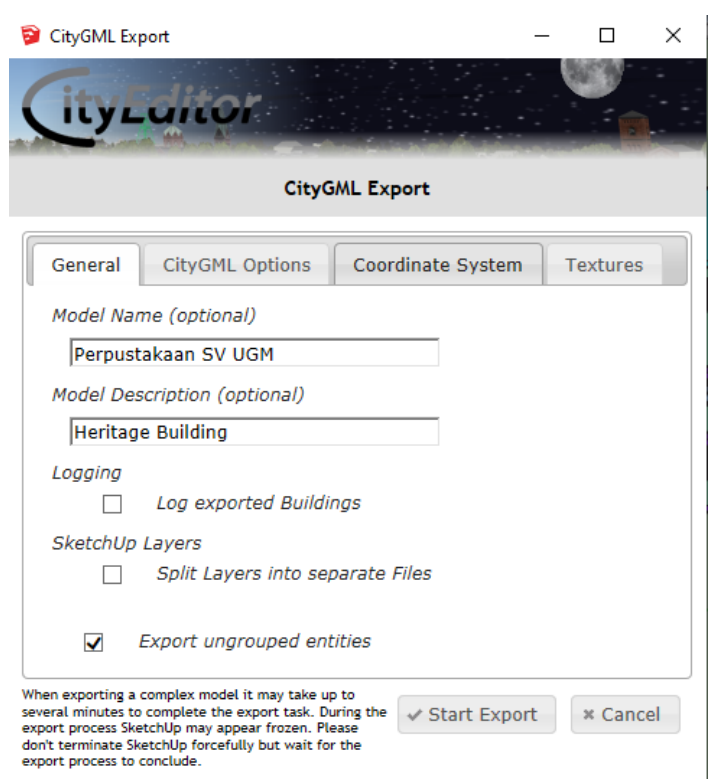

Gambar 3. Konversi CityGML dengan CityEditor 


\section{Basisdata Skema CityGML}

Pembangunan basisdata spasial penelitian dilakukan dengan menggunakan perangkat lunak PostgreSQL 11 (pgAdmin versi 4). Untuk membuat basisdata yang mendukung data spasial 3D, perangkat lunak PostgreSQL 11 (pgAdmin versi 4) memerlukan perangkat lunak pendukung. Penyimpanan data spasial dalam PostgreSQL 11 dimungkinkan dengan menambahkan extension PostGIS 2.5.2.

Selain itu, skema basisdata yang mendukung format CityGML perlu ditambahkan dalam perangkat lunak basisdata. Penambahan dilakukan dengan menginstal perangkat lunak 3DCityDB dan skema CityGML pada PostgreSQL.

\section{Impor Data Spasial}

Data spasial hasil tahapan konversi dalam format CityGML kemudian dimasukkan ke dalam basisdata dengan 3DCityDB Importer/Exporter. Dalam tahapan ini terlebih dahulu dilakukan koneksi ke basisdata Postgresql yang sudah dibuat. Data spasial dalam format CityGML kemudian diimpor dan disimpan dalam skema CityGML yang telah dibangun di basisdata tersebut.

\section{Analisis}

Analisis terhadap data spasial yang telah tersimpan dalam skema CityGML dilakukan dengan queri. Hal ini dilakukan untuk meninjau isi dari basisdata. Tahapan ini dilakukan dengan perangkat lunak PostgreSQL dengan menyusun queri SQL.

\section{HASIL DAN PEMBAHASAN}

Hasil tahapan konversi model 3D dalam penelitian ini berupa file format CityGML dengan ekstensi XML. Pada tahap konversi yang telah diuraikan sebelumnya, pada model 3D juga dilakukan georeferensi. Penentuan acuan meliputi kode EPSG yang digunakan, yaitu 32749. EPSG ini penting saat pembuatan basisdata maupun georeferensi model 3D karena menentukan sistem referensi yang digunakan.

Hasil tahapan konversi model 3D dalam penelitian ini berupa file format CityGML dengan ekstensi XML. Pada tahap konversi yang telah diuraikan sebelumnya, pada model 3D juga dilakukan georeferensi. Penentuan acuan meliputi kode EPSG yang digunakan, yaitu 32749 . EPSG ini penting saat pembuatan basisdata maupun georeferensi model 3D karena menentukan sistem referensi yang digunakan.

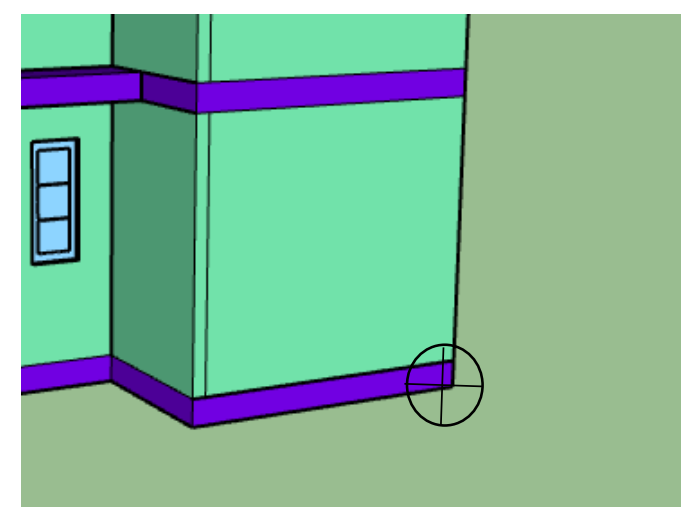

Gambar 4. Titik Sampel Georeferensi

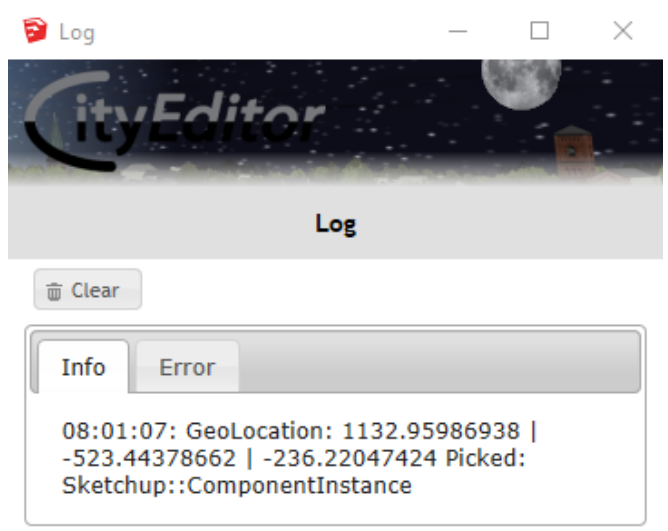

Gambar 5. Koordinat Sebelum Georeferensi

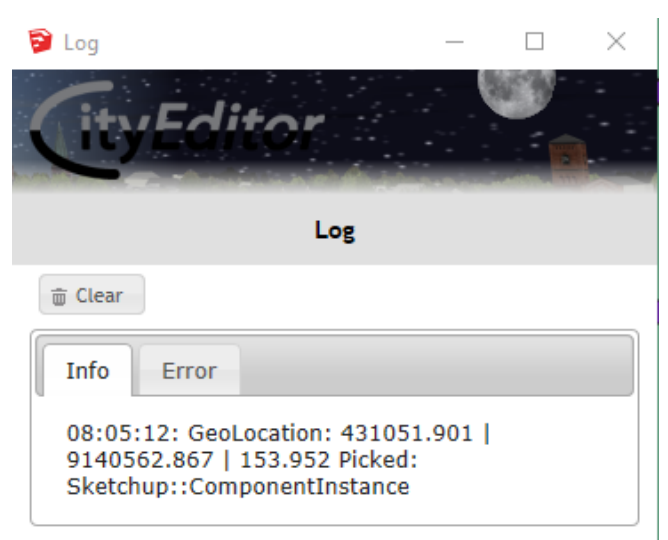

Gambar 6. Koordinat Setelah Georeferensi

Hasil penelitian berupa basisdata spasial 3D yang disimpan menggunakan skema CityGML. Basisdata ini diberi nama perpustakaan. Dalam perangkat lunak yang digunakan untuk membuat basisdata, ada satu skema bawaannya, yaitu public. Skema public ini digunakan untuk pembuatan basisdata tanpa melibatkan format CityGML. Saat 
dilakukan penambahan skema CityGML, ada dua skema tambahan dalam basisdata tersebut, yaitu citydb dan citydb_pkg. Skema ini memungkinkan penyimpanan yang mendetil dari suatu objek, tergantung tingkat ketelitian pemodelannya.

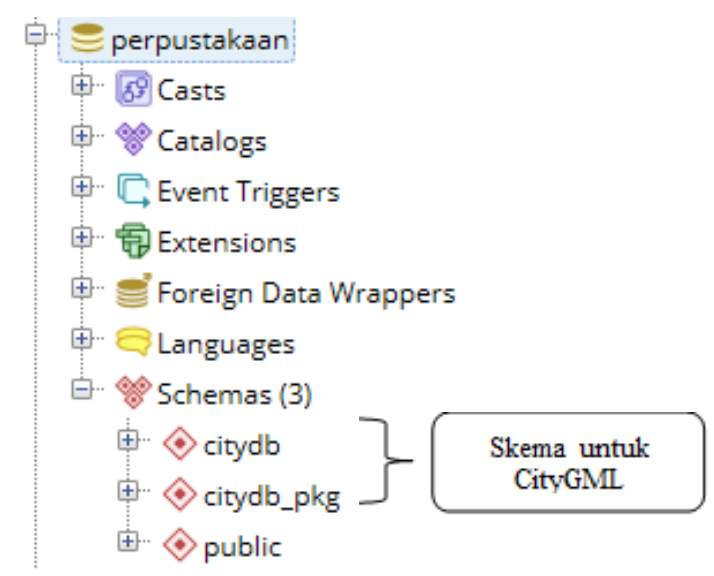

Gambar 7. Skema Tambahan CityGML

Di dalam kedua skema tersebut, berisi tabel-tabel untuk menyimpan geometri objek dan menunjukkan kaitan objek di sebuah kota beserta elemen-elemennya (semantik objek). Untuk skema citydb terdapat 66 tabel tetapi tidak semua tabel terisi. Tabel tersebut mencakup Geometric-topological model, Appearance model, dan Thematic Model. Thematic Model sendiri terdiri dari CityGML core, building model, bridge model, city furniture, Digital Terrain Model, generic objects and attributes, land use, transportation objects, tunnel model, water bodies dan vegetation objects.

Dalam penelitian ini objek utamanya adalah gedung yang masuk dalam kategori building model pada skema tersebut. Objek gedung memiliki bagian-bagian antara lain pintu, jendela dan atap sehingga tabel yang terisi adalah tabel-tabel yang berkaitan dengan building model tersebut saja.

\begin{tabular}{l|l}
\hline $\begin{array}{l}\text { classname } \\
\text { character varying (256) }\end{array}$ & $\begin{array}{l}\text { tablename } \\
\text { character varying (30) }\end{array}$ \\
\hline \hline _Feature & cityobject \\
\hline Building & building \\
\hline Polygon & surface_geometry \\
\hline
\end{tabular}

Gambar 8. Nama Tabel Untuk Menyimpan Objek Gedung

\begin{tabular}{l|l}
\hline $\begin{array}{l}\text { classname } \\
\text { character varying (256) }\end{array}$ & $\begin{array}{l}\text { tablename } \\
\text { character varying (30) }\end{array}$ \\
\hline BuildingWindow & opening \\
\hline BuildingDoor & opening \\
\hline
\end{tabular}

(a)

\begin{tabular}{|l|l|}
\hline $\begin{array}{l}\text { classname } \\
\text { character varying (256) }\end{array}$ & $\begin{array}{l}\text { tablename } \\
\text { character varying (30) }\end{array}$ \\
\hline BuildingFloorSurface & thematic_surface \\
\hline BuildingRoofSurface & thematic_surface \\
\hline BuildingWallSurface & thematic_surface \\
\hline
\end{tabular}

(b)

Gambar 8. Nama Tabel Untuk Menyimpan Semantik Pintu dan Jendela

Dari hasil queri untuk meninjau isi tabel, data objek gedung perpustakaan terisi pada tabel cityobject, building dan surface_geometry. Berdasarkan hal tersebut, data spasial gedung telah tersimpan. Namun demikian, detil objek seperti pintu dan jendela yang seharusnya didefinisikan di tabel opening dan thematic_surface tidak berhasil teridentifikasi untuk tabel tersebut

\section{KESIMPULAN}

Dalam mengolah data spasial terutama model 3D, penggunaan sistem koordinat lokal atau sistem koordinat pada perangkat lunak perlu menjadi perhatian. Pemahaman yang kurang tepat terhadap sistem koordinat dapat menyebabkan kesalahan posisi objek. Selain itu, dapat menghambat proses dalam perangkat lunak itu sendiri.

Data yang berkualitas menentukan hasil penyimpanan basisdata. Ketelitian model 3D tidak hanya dilihat dari LOD pemodelan objek, tetapi juga ditentukan oleh pendefinisian elemen yang tepat. Pendifinisian yang dimaksud berkaitan dengan penentuan layer saat melakukan pemodelan. Hal ini berpengaruh pada penyimpanan model 3D tersebut dalam skema CityGML.

\section{UCAPAN TERIMA KASIH}

Ketersediaan data penelitan ini didukung kerjasama PT. ASABA dan pihak peneliti dari Teknik 
Geomatika SV UGM yang melakukan pengukuran bersama. Oleh karenanya penulis mengucapkan terima kasih pada pihak yang terkait.

\section{DAFTAR PUSTAKA}

Aditya dan Laksono. (2017). LOD 1 - 3D CityModel for Implementing SmartCity Concept. Teknik Geodesi, Universitas Gadjah Mada, Yogyakarta, Indonesia.

Gröger, G., \& Plümer, L. (2012). CityGMLInteroperable semantic 3D city models. ISPRS Journal of Photogrammetry and Remote Sensing, 71, 12-33.

Kolbe, T. H. (2009). Representing and exchanging 3D city models with CityGML. 3D geoinformation sciences (pp. 15-31). Springer, Berlin, Heidelberg.

Kraak M. and Ormeling F. (2002). Kartografi : Visualiasasi Data Geospasial, Ed.2, diterjemahkan oleh Martha, S. Dkk. Yogyakarta: Gadjah Mada University Press.

OGC. (2012). OGC City Geography Markup Language (CityGML) Encoding Standard.
Preka, D. and Doulamis, A. (2016). 3D Building Modeling in LOD2 Using The CityGML Standard. 11th 3D Geoinfo Conference.

Prieto, I., Izkara, J. L., \& Delgado, F. J. (2012). From point cloud to web 3D through CityGML. 18th International Conference on Virtual Systems and Multimedia (pp. 405-412). IEEE.

Stadler, A., Nagel, C., König, G., \& Kolbe, T. H. (2009). Making interoperability persistent: A 3D geo database based on CityGML. 3D Geoinformation sciences (pp. 175-192). Springer, Berlin, Heidelberg.

Stoter, J. dan Oosterom, P.V. (2006). 3D Cadastre in an International Context. New York: Taylor \& Francis Group.

Subakti, B. (2015). Pembuatan Model Kota 3D Dalam Format CityGML Untuk Evaluasi Terhadap Rencana Tata Bangunan dan Lingkungan (RTBL). Tesis. Program Studi S2 Teknik Geomatika, Universitas Gadjah Mada, Yogyakarta, Indonesia.

Wyatt, J. C., dan Spiegelhalter, D. (2008). Field Trials of Medical Decision-Aids: Potential Problems and Solutions. Clayton, P. (ed.): Proceeding of 15th Symposium on Computer Applications in Medical Care, Vol.1 Ed 2. hal. 50-62. New York: McGraw Hill Inc. 